\title{
EDITORIAL
}

\section{CONFERÊNCIA NACIONAL DE SAÚDE MENTAL: EFETIVAR A REFORMA PSIQUIÁTRICA}

III Conferência Nacional de Saúde Mental, realizada de 11 a 15 de
dezembro de 2001 em Brasília, constitui um marco no processo da
reforma psiquiátrica. A definição do tema central - "Cuidar, sim. Excluir, não. Efetivando a reforma psiquiátrica com acesso, qualidade, humanização e controle social" - indicou sua articulação com as orientações da $11^{\text {a }}$ Conferência Nacional de Saúde e, também, com a insígnia proposta pela Organização Mundial da Saúde para o Dia Mundial da Saúde em 2001 (Brasil, 2001).

O tema central foi debatido a partir do eixo temático "Reorientação do modelo assistencial" e de quatro subtemas - recursos humanos (gestão com pessoas), financiamento, controle social e direitos, acessibilidade e cidadania - possibilitando o aprofundamento da reflexão sobre as diversas dimensões presentes no processo de reforma psiquiátrica e na implementação da política de saúde mental no contexto do SUS, nos níveis municipal, estadual e nacional, identificando os avanços, os impasses e as necessidades do momento.

Convocada após um conjunto de mobilizações de associações e grupos do campo da reforma e do movimento antimanicomial, e precedida de um intenso processo de participação nas conferências municipais, regionais e estaduais, a III Conferência reuniu cerca de 1700 participantes: gestores do sistema público, prestadores de serviços privados, representantes de instituições formadoras, de entidades de trabalhadores e da área de saúde e saúde mental, de organizações de direitos humanos, do movimento de luta antimanicomial, de movimentos populares, de associações de usuários e familiares dos serviços de saúde mental, e, também, convidados internacionais e representantes da OPAS e da OMS (Brasil, 2002).

As Conferências tem desempenhado um papel fundamental na definição e no aprofundamento dos rumos da reforma psiquiátrica e sua realização propicia o debate democrático necessário para a legitimidade da construção de uma política de saúde mental comprometida com a defesa dos direitos humanos e com a ruptura com as formas tradicionais da assistência psiquiátrica, que no Brasil resultaram no ineficaz modelo asilar.

A I Conferência Nacional de Saúde Mental realizada em 1987, após a $8^{\text {a }}$ Conferência Nacional de Saúde, assumiu a defesa dos direitos das pessoas com transtornos mentais e a necessidade de superação do então denominado "modelo hospitalocêntrico" e elaborou um conjunto de recomendações que estabeleceram as diretrizes iniciais para a constituição de um modelo assistencial extra hospitalar e comunitário.

Mas foi na II Conferência Nacional de Saúde Mental, realizada em 1992, que a crítica ao asilamento psiquiátrico, como expressão de uma determinada forma de relação com a loucura, pode ser aprofundada a partir da adoção de novos referenciais éticoteórico-políticos, do aprendizado das experiências locais e das iniciativas da política nacional de saúde mental no contexto do SUS, do fortalecimento e da organização do movimento social e da ampla mobilização em torno ao Projeto de Lei 3.657/89 que 
visava estabelecer a definitiva superação do aparato manicomial. As discussões realizadas delinearam as bases para a produção de modelos de atenção em saúde mental pautados nas diretrizes de afirmação dos direitos de cidadania das pessoas com transtornos mentais e de transformação do modelo assistencial. Destacou-se ainda, naquela Conferência, a presença organizada de usuários e familiares, expressando a qualidade do processo em curso e configurando um novo protagonismo que se potencializou nos anos que se seguiram.

Transcorridos nove anos da II Conferência Nacional de Saúde Mental, a realização da III Conferência reafirmou o significativo e insubstituível espaço das conferências como lugar democrático para o debate, a análise e a formulação de políticas públicas com a participação de todos os atores envolvidos e com controle social. Pode-se dizer ainda que essa Conferência se constituiu como fórum privilegiado para a avaliação da reforma psiquiátrica, compreendida como processo social complexo e multidimensional, e demonstrou a vitalidade e a singular riqueza de um percurso que busca construir a política a partir da afirmação de direitos, do reconhecimento da diversidade de saberes e, em particular, da validação das pessoas com a experiência do sofrimento psíquico e de seus familiares.

Os debates desenvolvidos em plenárias, grupos de trabalho, painéis específicos e na plenária final, ratificaram os princípios de superação do modelo asilar, com a construção de redes de atenção totalmente substitutivas, e de afirmação, construção e garantia dos direitos de cidadania das pessoas com transtornos mentais propostos na II Conferência e, ao mesmo tempo, evidenciaram a multiplicidade de exigências atuais para a efetiva concretização das diretrizes da reforma psiquiátrica no contexto do SUS e das políticas públicas orientadas para a transformação das relações entre as pessoas e as instituições, para a afirmação e extensão de direitos e para o enfrentamento das desigualdades sociais.

O Relatório Final da III Conferência apresenta um amplo e diversificado conjunto de proposições e estratégias, aprovadas na plenária final, que esperamos consiga orientar gestores, prestadores, usuários e familiares, técnicos, instituições formadoras, grupos interessados na construção de uma nova política de saúde mental e demais atores atuantes no controle social, quanto aos caminhos que pode e deve seguir a reforma psiquiátrica em nosso país, em direção à efetivação de um modelo de atenção em saúde mental que seja, ao mesmo tempo, capaz de inventar novas instituições e transformar as formas de lidar com a experiência da loucura, que, sem dúvida alguma, compõem a utopia de construção de uma nova sociedade, acalentada por tantos de nós.

\title{
REFERÊNCIAS
}

1. BRASIL. Ministério da Saúde. Conselho Nacional de Saúde. III Conferência Nacional de Saúde Mental - Caderno Informativo, Série D, n.15. Brasília, 2001.

2. BRASIL. Ministério da Saúde. Conselho Nacional de Saúde. III Conferência Nacional de Saúde Mental -Relatório final. Brasília, 2002.

\author{
Elisabete Ferreira Mângia \\ Fernanda Nicácio
}

Docentes do Departamento de Fisioterapia,

Fonoaudiologia e Terapia Ocupacional da FMUSP. 